\title{
Virtual Screening of Natural Metabolites as Candidate Drugs for Rheumatoid Arthritis
}

\author{
Joseph Christina Rosy, Ashok Bala M, Krishnan Sundar*
}

\begin{abstract}
Inflammation is a complex biological response to reject and heal any harmful stimuli created by pathogens, damaged cells or irritants. One of the more prevalent inflammatory disease found in $0.5-1.0 \%$ of the world's population is Rheumatoid arthritis (RA). RA is an autoimmune disease affecting the synovia. The actual reason for this disease is still unknown and is more complex to study. So, the drugs which are commercialized acts only to reduce the outcome of the disease, pain, by inhibiting the vital enzymes responsible for the synthesis of inflammatory mediators called prostaglandins. Cyclooxygenase- I and Cyclooxygenase- II are the commonly targeted enzymes by the current drugs in market. These drugs are reported to affect the normal physiological functions of various organs leading to side effects. PGE2 is the major prostaglandin involved in this disorder and found abundant in the affected synovia. mPGES-I is a membrane protein involved in the biosynthesis of PGE2 which has been reported as a novel drug target to treat RA. Though synthesized chemical compounds have higher anti-inflammatory activity; they are reported to possess a number of side effects. Thus a library of natural compounds are collected and screened virtually as mPGES-1 inhibitors using Autodock 4.2.
\end{abstract}

Keywords: inflammation, mPGES-1, prostaglandin rheumatoid arthritis

\section{INTRODUCTION}

Inflammation, the first protective response of the body to any injury or infection, is a complex process involving many types of cells to initiate the healing process. Arthritis is a joint disorder mainly due to inflammation in one or more joints. Though there are many types arthritis that have been reported worldwide, osteoarthritis and rheumatoid arthritis are the most prevalent types. Osteoarthritis is due to the wear and tear of cartilage tissues, over usage of joints and is associated with aging.

Rheumatoid arthritis (RA) is a chronic autoimmune disease in which the self-antigens are recognized as foreign leading to the destruction and inflammation of the synovial joints.

Revised Manuscript Received on December 29, 2019.

* Correspondence Author

Joseph Christina Rosy, Department of Biotechnology, School of Bio and Chemical Engineering, Kalasalingam Academy of Research and Education, Krishnankoil, Tamilnadu, India.

Email: j.christinarosy@klu.ac.in

Ashok Bala. M, Department of Biotechnology, School of Bio and Chemical Engineering, Kalasalingam Academy of Research and Education, Krishnankoil, Tamilnadu, India. Email: ashokbala1993@gmail.com

Krishnan Sundar, Department of Biotechnology, School of Bio and Chemical Engineering, Kalasalingam Academy of Research and Education, Krishnankoil, Tamilnadu, India. Email: sundarkr@klu.ac.in
Like other autoimmune diseases it arises from a variable combination of environmental factors, genetic susceptibility and inappropriate activation of immune responses but still the exact reason for rheumatoid arthritis is unknown. The synovial joints of RA patients were found to be infiltrated by monocytes/macrophages, $\mathrm{T}$ cells and $\mathrm{B}$ cells. These cells releases cytokines such as interleukins 1 and 17, and tumor necrosis factor $\alpha$, that play an important role in the production of prostaglandins [1].

Prostaglandins are small pro-inflammatory lipid mediators derived from arachidonic acid and are involved in numerous biological functions. Cyclooxygenase (COX) plays a key role in prostaglandin synthesis by converting arachidonic acid to prostaglandin $\mathrm{H} 2$ and then to prostaglandins [2]. Cyclooxygenase exist in two forms: the constitutive, COX-1 and the induced, COX-2. The non-steroidal anti-inflammatory drugs (NSAID) used to reduce inflammation inhibit both COX-1 and COX-2 through which prostaglandins synthesis is arrested. Selective COX-2 inhibitors were later developed to overcome the side effects due to NSAID [3].

Prostaglandin E2 (PGE2), a key mediator of inflammatory response, is abundant in the synovial fluid of rheumatoid arthritis patients [4]. Prostaglandin E synthase (PGES) catalyzes the final step of PGE2 biosynthesis. Three isoforms of PGES, cytosolic PGES (cPGES), microsomal PGES-1 (mPGES-1) and mPGES-2 are characterized by researchers. mPGES-1 is a glutathione dependent enzyme which shows coordinated induction with COX-2 under inflammatory conditions. Although cPGES is also a glutathione dependent enzyme, it is expressed in most of the tissues under normal conditions [5] However, mPGES-2 is not dependent on glutathione for its activity and is coupled to both COX-1 and COX-2 for PGE2 production [2]. mPGES is constitutively expressed and its activity is not significantly increased during inflammation, similar to cPGES. Hence, glutathione dependent mPGES-1could be considered as a promising therapeutic target for inflammatory diseases [6].

Drug designing has become an important part in the field of medicinal chemistry in recent years and in silico approaches are being used to predict the binding of small molecules to known target structure. There is a wide range of software packages available to predict the binding through molecular docking. AutoDock 4.2 is one such software which uses Lamarckian Genetic Algorithm as a search function. This algorithm is a hybrid genetic algorithm that uses a parameterized free-energy scoring function to estimate the binding energy. In this study, using AutoDock 4.2, a number of natural metabolites of marine and plants are screened to predict the compound that shows higher 
affinity towards mPGES-1, thereby inhibiting the synthesis of induced PGE2.

\section{MATERIALS AND METHODS}

\section{A. Retrieval of protein structure and ligands}

The three dimensional structure of microsomal prostaglandin E synthase-1 (mPGES-1) was collected from Protein Data Bank (www.rcsb.org).

Forty four marine compounds were selected from literature and their structures were collected from databases. A total of 76 plant compounds of Aloe vera, Withania somnifera, Morinda citrifolia collected from Dr. Dukes Phytochemical and Ethnobotanical Database were also used for the screening.

\section{B. Computational Details}

3GB RAM and Intel Core 2 duo E7500 processor (2.93GHz). Molecular docking studies were performed with Autodock 4.2 running in Debian version 9 operating system. Result analysis was performed with Discovery Studio Visualizer client 4.0

\section{Protein and Ligand Preparation}

A three dimensional structure of the protein molecule was downloaded from the Protein Data Bank (PDB) and it was prepared for docking by removing water and other heteroatoms, adding hydrogen bonds and charges using AutoDock 4.2.

A desired number of small compounds were obtained from various databases and they have been prepared by finding the root atom, a rigid portion of a ligand to which all other atoms are connected by non-rotatable bonds using AutoDock 4.2

To the prepared protein molecule a grid box was formed which sets the location and extend of the three dimensional area to be searched during the docking experiment

\section{Molecular Docking Studies}

The protein and all the 120 ligands were prepared for docking using the graphical user interface of Autodock tools. The preparation involved adding all hydrogen atoms to the proteins, which is a step necessary for calculation of partial atomic charges. Water molecules and heteroatoms were removed from the protein molecule [7]. By using the graphical user interface of Autodock tools, a 3D grid box was generated to embed the protein and, Grid parameters were set. Grid maps were calculated by running Autogrid 4 . Docking parameters were set by the docking wizard of Autodock Tools [8]. Conformation search was performed using Lamarckian Genetic Algorithm which runs for 100 cycles [9]. The binding energies for each conformation of the ligand with the proteins were determined by running Autodock 4 [10].

\section{E. Analysis of Docking}

Analysis of docking was performed by using the graphical user interface of AutoDock Tools and Discovery Studio Client 4.0. Binding energies of each conformation of docked compounds were noted and the best conformation was chosen based on the binding energy and number of hydrogen bonds that they form with the protein. Various types of interactions between ligand and receptor such as hydrogen bonds, hydrophobic interactions, Van der Waals and electrostatic interactions were visualized

\section{RESULTS}

\section{A. Retrieval of protein structure and ligands}

A three dimensional protein structure of mPGES-1 with $1.16 \AA$ resolution was downloaded from the Protein Data Bank (PDB ID: 4AL0) (Figure 1). The list of ligands taken for this study is listed in Table 2a-2d. Asn74, Glu77, His113, TYR117, Arg126, Ser127 are the active site amino acids interacting with the substrate glutathione (Fig1b)

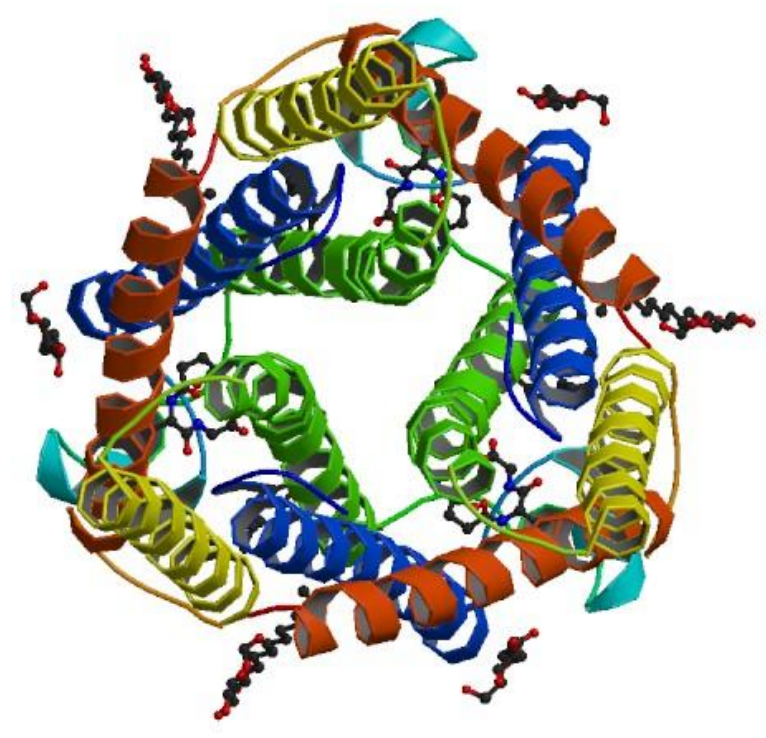

Figure 1a: Structure of mPGES-1.

\section{B. Analysis of Docking}

Initial studies were done with glutathione, the substrate for mPGES-1; which interacts with active site amino acids with a binding energy of $-6.06 \mathrm{Kcal} / \mathrm{mol}$. The interaction between glutathione and aloetic acid with the active site region of mPGES-1 is represented in the Figure 2.

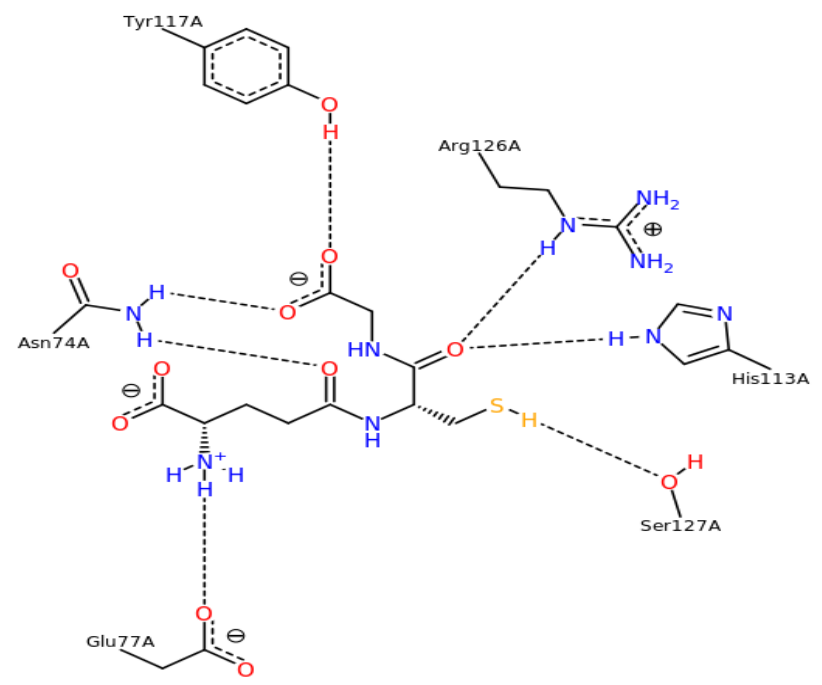


Figure 1b: Active site amino acids interacting with

\section{Glutathione}

Then, 120 marine and plant metabolites were docked at the active site of mPGES-1 to find their interaction as mPGES-1 inhibitor. The compounds with a binding energy of $<-6.06$ $\mathrm{kcal} / \mathrm{mol}$ were considered as strong binders and those with a binding energy of $>-6.06 \mathrm{kcal} / \mathrm{mol}$ were considered as weak binders. Compounds exhibited positive values were concluded as non-binders. The number of strong, weak and non-binders from each source are represented in the Figure 3.

Table2a: List of marine compounds docked with mPGES-1

\begin{tabular}{|l|l|}
\hline Isogeoditin A & Actinomadura Xanthone \\
\hline Cytonyc Acid B & Isoaptamine \\
\hline Certonardosterol Q6 & Amphidinolide X \\
\hline Steongylophorin 26 & Aplysinopsin \\
\hline Certonardosterol N1 & Caulibugulone F \\
\hline Laurenditerpenol & Isogranulatimide \\
\hline Neoamphimedine & Isogeoditin B \\
\hline Certonardosterol D2 & Cribrostatin 6 \\
\hline Certonardosterol C2 & Sarcodictyin A \\
\hline Dictyostatin 1 & Peloruside \\
\hline Certonardosterol A2 & Plakinamine K \\
\hline L- Cadinene & Plakortide N \\
\hline Iricinastatin A & Cytonyc Acid A \\
\hline Certonardosterol D & Renieramycin J \\
\hline Certonardosterol E3 & Jaspine B \\
\hline Ophiobolin A & Dolastatin 15 \\
\hline Certonardosterol E2 & Mycalazal 8 \\
\hline ertonardosterol D3 & Neohalichondramide \\
\hline Plakorstatin 1 & Phakellistatin 11 \\
\hline Smenospongorine & Microcinonamide A \\
\hline Lamellarin D & Microcinonamide B \\
\hline Andavadonic Acid & Tasiamide B \\
\hline
\end{tabular}

Table 2b: List of compounds from $W$. somnifera docked with mPGES-1

\begin{tabular}{|l|l|}
\hline Withanolide L & Quercetin \\
\hline Withanone & Scopoletin \\
\hline Withanolide D & Campesterol \\
\hline Sominone & $\begin{array}{l}2,3 \\
\text { Dehydrosomnifericin }\end{array}$ \\
\hline Withanolide F & Isopelletierine \\
\hline Daucosterol & Hydroxyproline \\
\hline Quresimine A & Pseudotropine \\
\hline Quinic Acid & Tropanol \\
\hline Quresimine B & Bellaradine \\
\hline 2,3 Dihydrowithaferin A & Hentriacontane \\
\hline
\end{tabular}

Table 2c: List of compounds from $A$. vera docked with mPGES-1

\begin{tabular}{|l|l|}
\hline Aloetic Acid & Arabinose \\
\hline Rhein & Aloenin \\
\hline Aloesin & Stearic Acid \\
\hline Aloesone & \\
\hline
\end{tabular}

Table2d: List of compounds from M. citrifolia docked with mPGES-1

\begin{tabular}{|l|l|}
\hline Rubian & Ethyldecamoate \\
\hline Asperulosidic acid & 2 methyl propanoiic acid \\
\hline Lucidin & 2 methyl butanoic acid \\
\hline Rubichloric acid & Myristic acid \\
\hline acid & Butyric acid \\
\hline Ursolic acid & Methyloleate \\
\hline Adipic acid & $\begin{array}{l}8,11,14, \text { eicosatrienoic } \\
\text { acid }\end{array}$ \\
\hline Phycion & Eugenol \\
\hline Alizarin & Eliaidic acid \\
\hline Biochanin A & z-6 dodeceno gamma \\
lactone
\end{tabular}

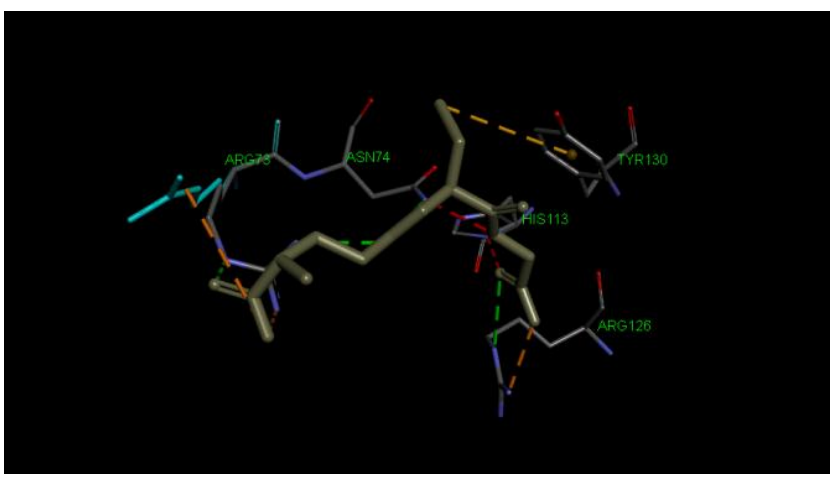

Figure 2: Interaction of mPGES with its natural substrate, glutathione

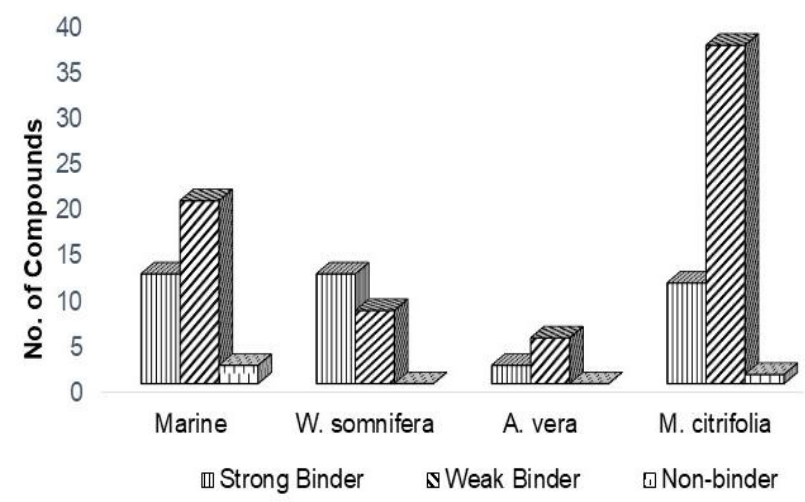


Figure 3: Analysis of binding of selected compounds with the drug target; mPGES-1

Aloetic acid, Rhein, Withanolide L, Rubian, and Withanone are the top 5 binders of mPGES-1; their source and binding energies are listed in the Table 3 . The interaction of these top 5 binders with the amino acids of mPGES-1 is given in the Figures 4 and 5 and the amino acids of mPGES- 1 that are involved in the interaction with the top five binders are provided in the Table 4.

Table 3: Top Five Binders of mPGES-1

\begin{tabular}{|l|l|l|}
\hline LIGAND NAME & SOURCE & $\begin{array}{l}\text { BINDING } \\
\text { ENERGY } \\
\text { (Kcal/mol) }\end{array}$ \\
\hline Aloetic acid & Aloe vera & -8.76 \\
\hline Rhein & Aloe vera & -8.15 \\
\hline Withanolide L & Withania somifera & -8.02 \\
\hline Rubian & Morinda citrifolia & -7.79 \\
\hline Withanone & Withania somifera & -7.75 \\
\hline
\end{tabular}

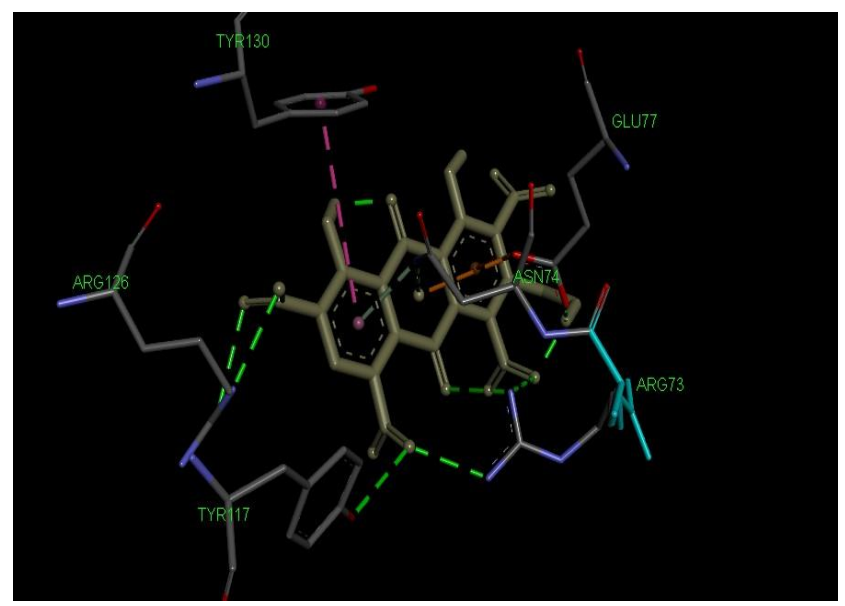

Figure 4: Interaction of aloetic acid with mPGES-1

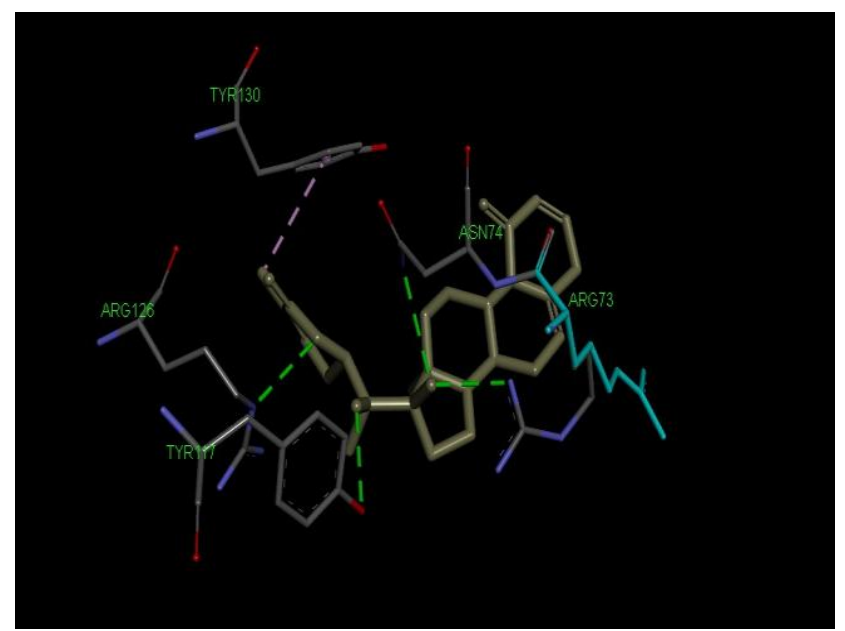

Figure 5: Interaction of withanolide $L$ with mPGES-1

Table 4: Amino acids of mPGES-1 involved in interaction with top five binders

\begin{tabular}{|l|l|l|l|l|l|}
\hline $\begin{array}{l}\text { Glutath } \\
\text { ione } \\
\text { (substr }\end{array}$ & $\begin{array}{l}\text { Aloetic } \\
\text { acid }\end{array}$ & Rhein & $\begin{array}{l}\text { Withan } \\
\text { olide L }\end{array}$ & Rubian & $\begin{array}{l}\text { Withan } \\
\text { one }\end{array}$ \\
\hline
\end{tabular}

\begin{tabular}{|l|l|l|l|l|l|}
\hline ate) & & & & & \\
\hline Asn74 & Arg73 & Arg73 & Arg73 & Arg73 & Arg73 \\
\hline Glu77 & Asn74 & Asn74 & Asn74 & Asn74 & Glu77 \\
\hline His113 & Glu77 & His 113 & Try117 & Glu77 & His 113 \\
\hline Tyr & Try117 & Ser 127 & Arg126 & Pro 81 & Arg126 \\
\hline Arg126 & Arg126 & Arg126 & Try130 & Arg126 & Try130 \\
\hline Ser127 & Try130 & Thr131 & & & \\
\hline
\end{tabular}

\section{DISCUSSION}

In recent days natural products are extensively used in the development of drugs due to their availability and biological activity [11]. In the current study, 120 natural compounds of marine and plant sources were docked to find their interaction with the active site region of mPGES-1 so that they can be further tested as a lead molecule for the inhibition of mPGES-1 activity.

Top five compounds that exhibit higher binding affinity toward the mPGES-1 are listed with their binding energies in the Table 3. All these five compounds have their origin from plants indicating that plant compounds have greater ability to bind with mPGES-1 than the marine compounds. Although many marine compounds have been studied in the past few decades for their potent biological activity [12], they exhibited a weak binding ability toward mPGES-1 than the plant compounds.

The top two binders aloetic acid and rhein are from $A$. vera, with a binding energy of -8.76 and $-8.15 \mathrm{Kcal} / \mathrm{mol}$ respectively which is considerably lower than glutathione. Also they interact with 4 out of 6 active site amino acids. Biological activity of aloetic acid has not been reported yet, so this compound can be studied further for expressing its anti-inflammatory effect. Antiproliferation studies on anthraquinone derivatives indicated that rhein has the ability to inhibit expression of certain genes responsible for breast cancer [13].

Withanolide L and withanone are the other two top binders of mPGES-1 obtained from $W$. somnifera, exhibiting a binding energy of -8.02 and $-7.75 \mathrm{Kcal} / \mathrm{mol}$ respectively. Withanone is a compound derived from leaves of $W$. somnifera. Incidentally, this compound has already been suggested as a potential candidate molecule for cancer through docking studies [14]. Rubian is obtained from the bark of $M$. citrifolia, a plant reported to have a broad range of therapeutic effects [15]. Rubian exhibited a binding energy of $-7.79 \mathrm{Kcal} / \mathrm{mol}$.

The results obtained from the present study clearly indicate that the natural metabolites show a higher potential in the development of new drugs. Aloetic acid, rhein, withanolide $\mathrm{L}$, rubian and withanolide $\mathrm{D}$ are the top five binders obtained as a result displays a better binding with the mPGES- 1 than its original substrate, glutathione, leaving a hint that they can be used as a possible drug for the inhibition of mPGES-1. Since these five compounds 
have their origin from plants, they can be easily synthesized. Natural compounds are already been reported to have high biological activity so, these compounds can be further utilized for in vivo studies and can be tested as a potential drug compound for rheumatoid arthritis and other inflammatory disorders.

\section{KNOWLEDGEMENT}

K.S. was supported by a grant from SERB, New Delhi, India (Grant No: SR/SO/HS-0248/2012 \& 30/09/2012).

\section{REFERENCES}

1. J. Zwerina, K. Redlich, G. Schett, and J.S. Smolen, "Pathogenesis of rheumatoid arthritis: targeting cytokines," Ann N Y Acad Sci, vol. 1051, pp.716-729, 2005.

2. M. Murakami, K. Nakashima, D. Kamei, S. Masuda, Y. Ishikawa, T. Ishii, Y. Ohmiya, K. Watanabe and I. Kudo, "Cellular prostaglandin E2 production by membrane-bound prostaglandin E synthase-2 via both cyclooxygenases-1 and 2," J Biol Chem, vol. 278, pp. 37937-37947, 2003.

3. G. A. FitzGerald and C. Patrono, "The coxibs, selective inhibitors of cyclooxygenase-2," N Engl J Med, vol. 345, pp.433-442, 2001.

4. D. Egg, R. Gunther, M. Herold and F. Kerschbaumer, "Prostaglandin E2 and F2 alpha concentrations in the synovial fluid in rheumatoid and traumatic knee joint disease," Z Rheumatol, vol. 39, pp.170-175, 1980.

5. T. Tanioka, Y. Nakatani, N. Semmyo, M. Murakami, I. Kudo, "Molecular identification of cytosolic prostaglandin E2 synthase that is functionally coupled with cyclooxygenase- 1 in immediate prostaglandin E2 biosynthesis," J Biol Chem, vol. 275, pp.32775-32782, 2000.

6. B. Samuelsson, R. Morgenstern and P. J. Jakobsson, "Membrane prostaglandin E synthase-1: A novel therapeutic target," Pharmacol Rev, vol. 59, pp.207-224, 2007.

7. R. S. Yedidi, Z. Liu, I. A. Kovari, P. M. Woster and L. C. Kovari, "P1 and $\mathrm{P} 1$ ' para-fluoro phenyl groups show enhanced binding and favorable predicted pharmacological properties: Structure-based virtual screening of extended lopinavir analogs against multi-drug resistant HIV-1 protease," J Mol Graph Model, vol. 47, pp.18-24, 2014.

8. H. Ravinarayanan, J. Christina Rosy, R. Somavarapu, S. Ayswarya, B. Sundararajan, R. Subburaj and K. Sundar, "Anti-viral drugs against Ebola: A structure based virtual screening approach,” Ind J Biotechnol, vol. 17, pp.176-184, 2018.

9. G. M. Morris, R. Huey, W. Lindstrom, M. F. Sanner, R. K. Belew, R. K., D. S. Goodsell and A. J. Olson, "Autodock4 and AutoDockTools4: automated docking with selective receptor flexibility," J Comput Chem, vol.30, pp.2785-2791, 2009.

10. S. Cosconati, S. Forli, A. L. Perryman, R. Harris, D. S. Goodsell, and A. J. Olson, "Virtual screening with AutoDock: theory and practice" Expert Opin. Drug Discov, vol.5, pp.597-607, 2010.

11. A. M. Clark, "Natural products as a resource for new drugs," Pharm Res, vol. 13, pp. 1133-1141, 1996.

12. K. Senthilkumar, K., and S. Kim, "Marine invertebrate natural products for anti-inflammatory and chronic diseases," Evid Based Complement Alternat Med, vol. 2013, 272859, 2013.

13. C.Y. Chang, H.L. Chan, H.Y. Lin, T.D. Way, M.C. Kao, M.Z. Song, Y.J. Lin and C.W. Lin, "Rhein induces apoptosis in human breast cancer cells,” Evid Based Complement Alternat Med, vol. 2012, 952504, 2012.

14. V. P. Wadegaonkar and P. A. Wadegaonkar, "Withanone as an inhibitor of survivin: a potential drug candidate for cancer therapy," J Biotechnol, vol. 168, pp.229-233, 2013.

15. M. Y. Wang, B. J. West, C. J. Jensen, D. Nowicki, C. Su, A. K. Palu and G. Anderson, "Morinda citrifolia (Noni): a literature review and recent advances in Noni research," Acta Pharmacol Sin, vol. 23, pp.1127-1141, 2002.

\section{AUTHORS PROFILE}

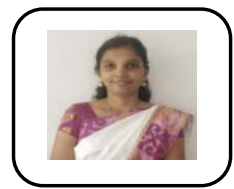

Virulence'.
Christina Rosy, Joseph is currently working as an Assistant Professor in the Department of Biotechnology, Kalasalingam Academy of Research and Education. She has completed her Masters' in Biotechnology and pursuing $\mathrm{PhD}$ on 'Iron and

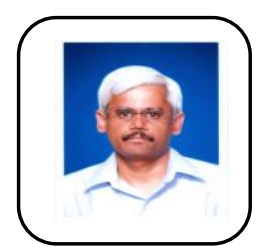

Dr Krishnan Sundar is a Professor of Biotechnology at Kalasalingam Academy of Research and Education. He received his Ph.D. degree in Microbiology from Madurai Kamaraj University. His research interests include target identification and drug design using in silico tools. 